\title{
Impact of Type of Sport, Gender and Age on Red Blood Cell Deformability of Elite Athletes
}

Authors

Fabian Tomschi ${ }^{1}$, Wilhelm Bloch ${ }^{1,}{ }^{2}$, Marijke Grau ${ }^{1}$

\section{Affiliations}

1 Molecular and Cellular Sports Medicine, German Sport University Cologne, Germany

2 The German Research Center of Elite Sport (momentum), German Sport University Cologne, Germany

\section{Key word}

erythrocyte flexibility, hematocrit, mean cellular volume, training

accepted 07.09.2017

\author{
Bibliography \\ DOI https://doi.org/10.1055/s-0043-119879 \\ Published online: 17.11.2017 \\ Int J Sports Med 2018; 39: 12-20 \\ (c) Georg Thieme Verlag KG Stuttgart · New York \\ ISSN 0172-4622
}

\section{Correspondence}

Mr. Fabian Tomschi

Deutsche Sporthochschule Koln

Molecular and Cellular Sports Medicine

Am Sportpark Müngersdorf 6

50933 Koln

Germany

Tel.: +49/221/49825 010, Fax: + 49/221/49828370

fabian.tomschi@gmx.de

\begin{abstract}
Our objective was to detect possible differences in red blood cell (RBC) deformability of elite athletes performing different types of sports and being of different age and gender.182 athletes were included in this cross-sectional study. RBC deformability was measured using the laser-assisted optical rotational cell-analyzer. Maximal elongation index $\left(\mathrm{EI}_{\max }\right)$ and shear stress at half-maximum deformation ( $\mathrm{SS}_{1 / 2}$ ) were calculated. The ratio $\mathrm{SS}_{1 / 2} / \mathrm{EI}_{\text {max }}\left(\mathrm{El}_{\text {Ratio }}\right)$ was calculated with low values representing high RBC deformation. Hematocrit (Hct) and mean cellular volume (MCV) were determined in venous blood. Overall RBC deformability did not differ between male and female athletes but, when separated by age of the subjects, RBC deformability increased with age in male but not in female athletes. RBC deformability was lower in Combat sports compared other sport groups. Hct was higher in male compared to female athletes while no difference was observed for MCV. MCV and $\mathrm{Hct}$ increased with increasing age. A negative correlation was found between the $\mathrm{El}_{\text {Ratio }}$ and $\mathrm{MCV}$ and between $\mathrm{El}_{\text {Ratio }}$ and Hct. Conclusion: RBC deformability is influenced by age and endurance rate of the sport which suggests that the RBC system may adapt to changing conditions such as adolescence with the onset effects of sex hormones or physical exercise.
\end{abstract}

\section{Introduction}

Human red blood cells (RBC) with a life span of around 120 days are very heterogeneous in terms of cell age [12].The major function of RBC is to deliver oxygen to muscles and organs in the human body. By arranging themselves in a "single-file flow" and being highly deformable RBC can pass capillaries of different caliber, which are, especially in the microcirculation, smaller than their own caliber. This is necessary to provide optimal oxygen diffusion [22].

The age of RBC crucially influences RBC deformability. It has been previously shown that old and high density RBC are less deformable than young, low density RBC. This has been associated to a reduction in mean cellular volume (MCV) with young RBC showing the highest MCV values and a continuous decrease in MCV with increasing RBC age [5]. Decreased MCV and thus increased cell density was shown to alter the surface-to-volume ratio [6].This sur- face-to-volume ratio, but also the geometric and mechanical properties of the cell membrane and the cytoskeleton, critically affect deformation of RBC [21].

Aerobic/anaerobic endurance and strength performance of athletes particularly depends on oxygen supply in the microcirculation $[10,18,30]$. Regular physical training as performed by athletes increases RBC mass but also RBC deformability and MCV values of the RBC because of a younger average RBC population [30]. Besides, endurance exercise and high workloads reduce hematocrit (Hct) levels which is explained by an increase in plasma volume. Increase in RBC mass but reduction in total Hct is called sports anemia [29].

Overall, the effects of exercise on RBC deformability depend on intensity and duration of exercise and may vary between the study populations $[24,31,39]$. Long term effects of exercise, the differentiation 
between different types of sport, gender differences and changes during adolescence have never been investigated so far. Thus, the aim of this study was to measure RBC deformability, Hct and MCV at rest to detect possible differences between male and female top-class athletes of different age who perform different sport types.

\section{Methods}

This study is in accordance with the ethical guidelines outlined by the IJSM [17] and was approved by the Ethics Committee of the German Sport University Cologne.

\section{Participants}

182 competitive athletes (mean age $18.42 \pm 4.72$ years (Range: 10.00 33.00 ); weight $64.76 \pm 13.59 \mathrm{~kg}$ (Range: $26.00-103.00$ ); height $174.24 \pm 11.33 \mathrm{~cm}$ (Range: $136.00-196.00)$ ), who perform on topnational or international level, were recruited for this study. Of these were 90 females (age 17.61 \pm 4.75 years (Range: $10.00-33.00$ ); weight $60.59 \pm 11.11 \mathrm{~kg}$ (Range: $26.00-78.00$ ); height $171.11 \pm 10.50 \mathrm{~cm}$ (Range: 136.00-191.00)) and 92 males (age $18.22 \pm 4.58$ years (Range: 11.00-31.00); weight 68.88 $\pm 14.58 \mathrm{~kg}$ (Range: $30.00-$ 103.00); height 177.60 \pm 11.27 (Range: 145.00-196.00)).

\section{Laboratory testing}

Capillary blood was sampled from the finger pulp into heparinized capillaries (EKF Diagnostics Holdings plc, Wales). Additionally, venous blood was drawn into EDTA vacutainer (Becton, Dickinson and Company, USA) to determine Hct and MCV values using the Sysmex Digitana KX-21 N hematology analyzer (Sysmex Deutschland $\mathrm{GmbH}$, Germany). Blood was sampled under fasting conditions at rest and immediately processed.

Capillary anticoagulated blood was immediately mixed with a viscous polyvinylpyrrolidone solution (RR Mechatronics, The Netherlands; 1:250 ratio) [31]. RBC deformability was measured using the Laser Assisted Optical Rotational Cell Analyzer (LORCA, RR Mechatronics, The Netherlands) as previously described [16]. RBC deformability was measured for nine shear stresses between 0.3 and 50 Pa with a laser beam directed through the samples throughout the measurements and an elongation index (El) was calculated by the LORCA software from the vertical and horizontal radius of the diffraction pattern. The theoretical maximal El at infinite shear stress $\left(\mathrm{EI}_{\max }\right)$ and the shear stress at half-maximum deformation $\left(\mathrm{SS}_{1 / 2}\right)$ were calculated using non-linear regression according to Baskurt and colleagues [1]. $\mathrm{El}_{\text {Ratio }}=\mathrm{SS}_{1 / 2} / \mathrm{El}_{\max }$ was finally calculated according to Baskurt and colleagues [2] with higher values representing lower $\mathrm{RBC}$ deformability. This $\mathrm{El}_{\text {Ratio }}$ was shown to be more robust in reflecting alterations of deformability and having similar power compared to the individual values $\mathrm{EI}_{\max }$ and $\mathrm{SS}_{1 / 2}$, while reducing data to one parameter [2].

\section{Distribution of subjects}

Deformability data, MCV and Hct values were then analyzed according to age and type of sport with respective subdivision to compare data of females and males. Athletes were grouped into age groups 11 to 13 years, 14 to 17 years, 18 to 22 years and 23 to 33 years [38]. Number of data analyzed for the age groups were as follows: Age group 11 to 13 years ( $n=25 ; 11$ female, 14 male), 14 to 17 years ( $n=67 ; 46$ female, 21 male), 18 to 22 years ( $n=41 ; 15$ female, 26 male) and 23 to 33 years ( $n=49 ; 18$ female, 31 male).

Numbers of samples analyzed for type of sport were as follows: Team sport ( $n=39 ; 28$ female, 11 male, age $16.84 \pm 4.18$ years), return sport ( $n=41 ; 29$ female, 12 male, age $17.8 \pm 5.25$ years), combat sport ( $n=48$; 11 female, 37 male, age $19.94 \pm 4.63$ years), endurance-strength sport ( $\mathrm{n}=20 ; 10$ female, 10 male, age $19.80 \pm 3.82$ years) and endurance sport $(n=34 ; 12$ female, 22 male, age $17.97 \pm 4.67$ years). The only significant difference in age between the groups was found between Team sports and Combat sports $(P<0.05)$. In between one sport type the only significant difference in age considering gender is in the Team sport group in which females were younger than males (male 20.80 \pm 4.61 , female $15.43 \pm 3.00 ; \mathrm{P}<0.01)$.

Participants were assigned to sport type groups as done before [40] with the exception that endurance athletes were further subdivided into "Endurance sports" and "Endurance-Strength sports". Sport groups included athletes of the following disciplines: Team sport (Basketball, Field-Hockey, Soccer, Handball, Canoe Polo, American Football), Return sport (Tennis, Badminton, Table Tennis, Volleyball), Combat sport (Boxing, Fencing, Judo, Taekwondo), Endurance-Strength (400 m Sprint, 400 m Hurdles, Canoe Slalom, Heptathlon, Rowing, Cross-Fit) and Endurance sport (Racing Bicycle, Swimming, Triathlon, Nordic Combination, Long-Distance Running).

\section{Statistical analysis}

Statistical analyses of the data were performed by using statistics software package Graph-PadPrism 6 (La Jolla, USA). The data are expressed as mean \pm standard deviation (SD) unless described otherwise. A two-way ANOVA with the factors 'gender' X 'sport type' and 'gender' $X$ 'age group' was applied to determine differences in $\mathrm{El}_{\text {max }}, \mathrm{El}_{\text {Ratio }}, \mathrm{SS}_{1 / 2}, \mathrm{MCV}$ and Hct. In case of significant differences, Tukey post hoc analyses were used to locate differences between age groups and sport type groups. Bonferroni post hoc tests were performed to reveal significant differences in interactions between 'gender' $X$ 'sport type' and 'gender' $X$ 'age group'. Correlation and linear regression analyses were performed and $R$ and $R^{2}$ were presented. Statistical differences were considered to be significant for values of $\mathrm{P} \leq 0.05\left({ }^{*}\right), \mathrm{P} \leq 0.01\left({ }^{* *}\right)$ and $\mathrm{P} \leq 0.001\left({ }^{* * *}\right)$.

\section{Results}

\section{Red blood cell deformability}

Statistic analyses with gender and age group as factors revealed a significant $(P<0.01)$ effect of the age group $X$ gender interaction ( $\triangleright$ Fig. 1a) and age group $(\mathrm{P}<0.01)$ on $\mathrm{El}_{\text {Ratio }}(\triangleright$ Fig. 1b). Gender did not have any effect on $\mathrm{El}_{\text {Ratio }}(\triangleright$ Fig. 1a). Post hoc analyses revealed that age groups 11 to 13 and 14 to 17 had a higher El Ratio compared to the age group 23 to 33 and that age group 11 to 13 had a higher $\mathrm{El}_{\text {Ratio }}$ compared to age group 18 to 22 ( $>$ Fig. 1b). Separated by gender, the male age group 11 to 13 showed a significantly higher $(P<0.05) \mathrm{El}_{\text {Ratio }}$ compared to female athletes. Within male athletes, the age group 11 to 13 showed significantly $(\mathrm{P}<0.05)$ higher $\mathrm{El}_{\text {Ratio }}$ compared to other age groups ( $>$ Fig. 1a). 
Analyses with gender and sport type as factors revealed a significant $(P<0.01)$ effect of sports type on $\mathrm{El}_{\text {Ratio }}(\triangleright$ Fig. 1C). The sport type $X$ gender interaction did not show any effect on $\mathrm{El}_{\text {Ratio }}$ ( $\triangleright$ Fig. 1d). Post hoc analyses revealed that the $\mathrm{EI}_{\text {Ratio }}$ of Combat sports was higher $(\mathrm{P}<0.01)$ compared to Endurance, EnduranceStrength and Court-return sports ( $\triangleright$ Fig. 1c). Separated by gender, female Team and Court-return sport athletes showed higher $(\mathrm{P}<0.05) \mathrm{El}_{\text {Ratio }}$ compared to male athletes. Within male athletes, athletes of Court-return and Endurance-Strength sports had lower $(\mathrm{P}<0.05) \mathrm{El}_{\text {Ratio }}$ compared to Combat sports ( $>$ Fig. 1d).

Analyses with gender and age group as factors revealed a significant effect $(P<0.05)$ of the age group $X$ gender interaction ( $\triangleright$ Fig. 2a) and age group $(\mathrm{P}<0.05)$ on $\mathrm{EI}_{\max }(\triangleright$ Fig. 2 b). Gender did not have any effect on $\mathrm{EI}_{\max }(\triangleright \mathbf{F i g}$. 2a). Post hoc analyses revealed that age group 23 to 33 had lower $\mathrm{EI}_{\max }$ compared to age groups 14 to 17 and 18 to 22 ( $P<0.01$; Fig. 2b). Separated by gender, male athletes age 11 to 13 showed a higher $\mathrm{EI}_{\max }(\mathrm{P}<0.001)$ compared to females of this age. Within male athletes, age group 22 to 23 showed lower $\mathrm{EI}_{\max }$ compared to age groups 11 to 13 and 18 to $22(\mathrm{P}<0.01)$. Within female athletes, age group 11 to 13 showed lower $\mathrm{EI}_{\max }$ values compared to age groups 14 to 17 and 18 to 22 $(\mathrm{P}<0.01$; Fig. 2a).

Analyses with gender and sport type as factors revealed a significant $(P<0.05)$ effect of sport type on $\mathrm{El}_{\max }(\triangleright$ Fig. $2 \mathrm{C})$. The sport type $X$ gender interaction did show an effect on $\mathrm{EI}_{\max }(P<0.05)$. Post hoc analyses revealed that the $\mathrm{EI}_{\max }$ of Combat sports was higher compared to Court-return and Endurance-Strength sports ( $\mathrm{P}<0.05$; $>$ Fig. 2c). Separated by gender, female athletes of Team sports showed a higher $\mathrm{EI}_{\max }(\mathrm{P}<0.05)$ compared to male athletes. Within male athletes, Combat sports showed higher $\mathrm{EI}_{\max }$ values compared to Team sports $(P<0.01)$ and Court-return Sports $(\mathrm{P}<0.05)$. Within in female athletes, no difference was observed ( Fig. 2d).

Analyses with gender and age group as factors revealed a significant effect $(P<0.01)$ of the age group $X$ gender interaction ( $\triangleright$ Fig. 3a) and age group $(\mathrm{P}<0.05)$ on $\mathrm{SS}_{1 / 2}(\triangleright$ Fig. $3 \mathbf{b})$. Gender did not have any effect on $\mathrm{SS}_{1 / 2}(\triangleright \mathbf{F i g}$. 3a). Post hoc analyses revealed that age group 23 to 33 had lower $\mathrm{SS}_{1 / 2}$ values compared to age groups 11 to $13(P<0.001)$ and 14 to $17(P<0.01$; Fig. 3 b $)$. Separated by gender, male athletes age 11 to 13 showed higher $\mathrm{SS}_{1 / 2}$ values compared to female athletes $(P<0.01)$. Within male athletes, age group 23 to 33 had lower $\mathrm{SS}_{1 / 2}$ values compared to age group 11 to $13(P<0.001)$ and 18 to $22(P<0.05)$. Age group 11 to 13 had higher $S_{1 / 2}$ values compared to age group 14 to 17 $(\mathrm{P}<0.01)$ and age group 18 to $22(\mathrm{P}<0.05)$. Within female athletes, no difference was observed ( $>$ Fig. 3a).

Analyses with gender and sport type as factors revealed a significant $(P<0.01)$ effect of sport type on $\mathrm{SS}_{1 / 2}$ ( $>$ Fig. 3c). The sport type $X$ gender interaction did not show any effect on $\mathrm{SS}_{1 / 2}$. Post hoc analyses revealed that Combat sports showed a higher $\mathrm{SS}_{1 / 2}$ compared to court-return sports, Endurance-Strength sports and Endurance sports $(P<0.01$; Fig. 3 C). Separated by gender, male athletes of Team sports and Court-return sports had lower $\mathrm{SS}_{1 / 2}$ values compared to male athletes $(\mathrm{P}<0.05)$. Within male athletes, Combat sports showed higher $\mathrm{SS}_{1 / 2}$ values compared to Team, Endurance-Strength sports $(P<0.05)$ and Court-return sports $(P<0.01)$. Within female athletes, no difference was observed ( $\triangleright$ Fig. 3d).
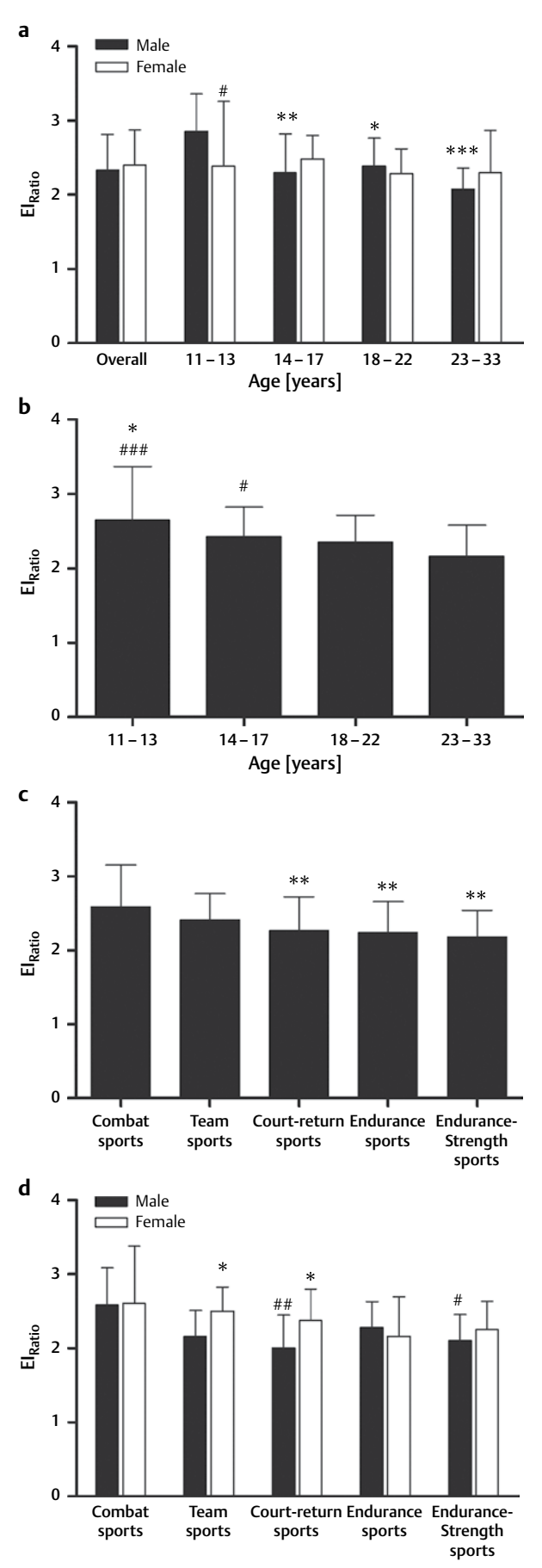

- Fig. 1 a ElRatio of athletes separated by age and gender. \# significant difference $(P<0.05)$ to male of the same age group; * Significant difference $(\mathrm{P}<0.05),{ }^{* *}(\mathrm{P}<0.01),{ }^{* * *}(\mathrm{P}<0.001)$ to male age group 11 to 13 . $\mathbf{b}$ ElRatio of athletes separated by age groups. \# significant difference $(P<0.05)$, \#\#\# $(P<0.001)$ to age group 2333; * Significant difference $(P<0.05)$ to age group 18-22. c EIRatio of athletes separated by sport type. ${ }^{* *}$ Significant difference $(P<0.01)$ to Combat sports. $\mathbf{d}$ EIRatio of athletes separated by sport type and gender. ${ }^{*}$ Significant difference $(P<0.05),{ }^{* *}(P<0.01)$ to male of same sport type; \# significant difference $(P<0.05)$, \#\# $(P<0.01)$ to Combat sports. 


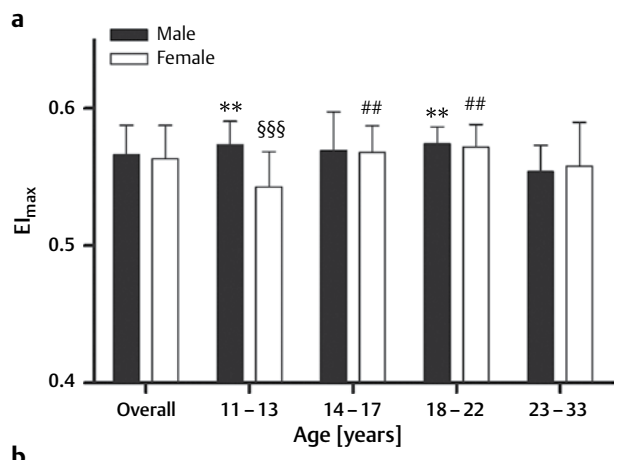

b
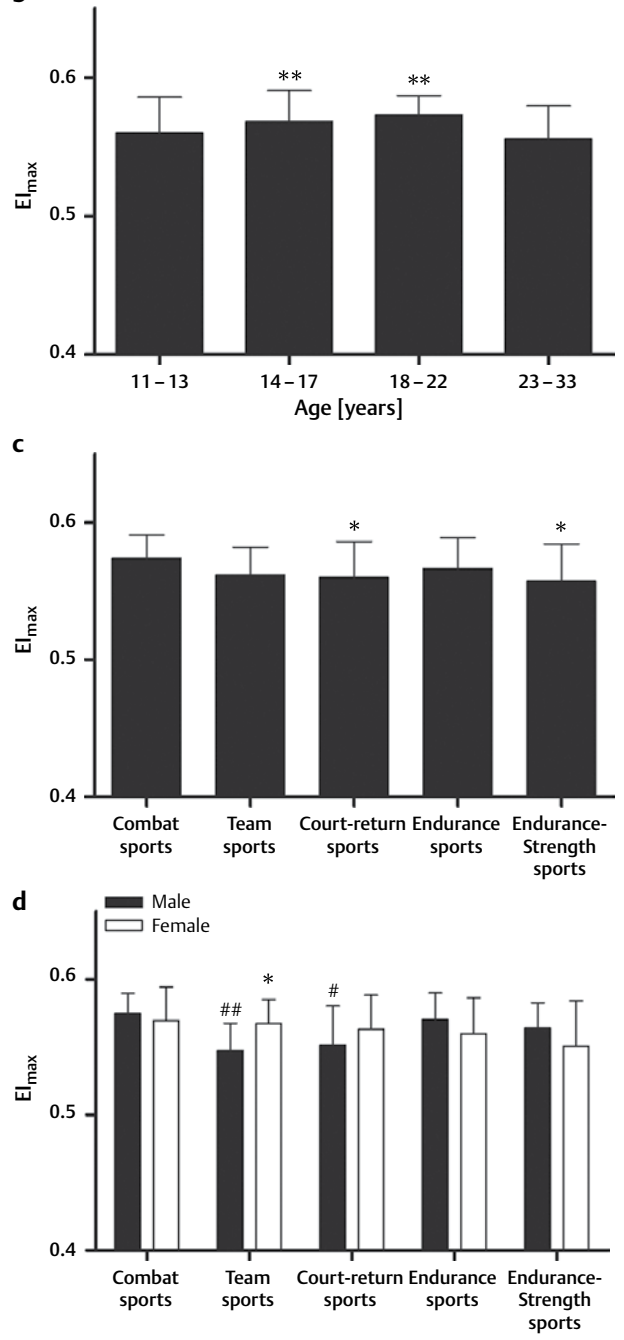

- Fig. 2 a Elmax of athletes separated by age and gender. ** Significant difference $(P<0.01)$ to male age group 23 to 33; \#\# significant difference $(P<0.01)$ to female age group 11 to $13 ; \S \S \S$ significant difference $(P<0.001)$ to male of same age group. $\mathbf{b}$ Elmax of athletes separated by age groups. ${ }^{* *}$ Significant difference $(P<0.01)$ to age group 23 to 33. c Elmax of athletes separated by sport type. * Significant difference $(P<0.05)$ to Combat sports. $\mathbf{d}$ Elmax of athletes separated by sport type and gender. * Significant difference $(P<0.05)$ to male of same sport; \# significant difference $(P<0.05)$, \#\# $(\mathrm{P}<0.01)$ to male Combat sports.

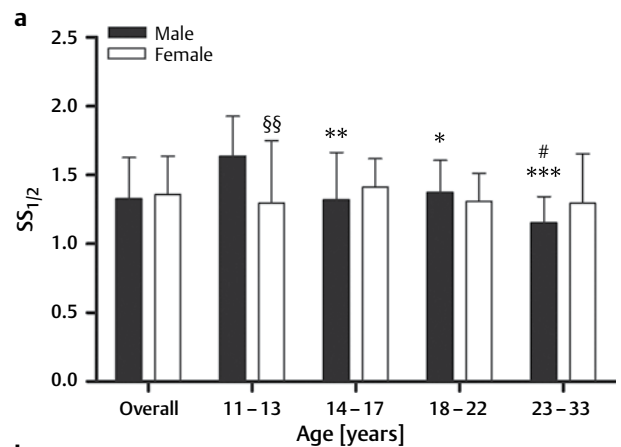

b
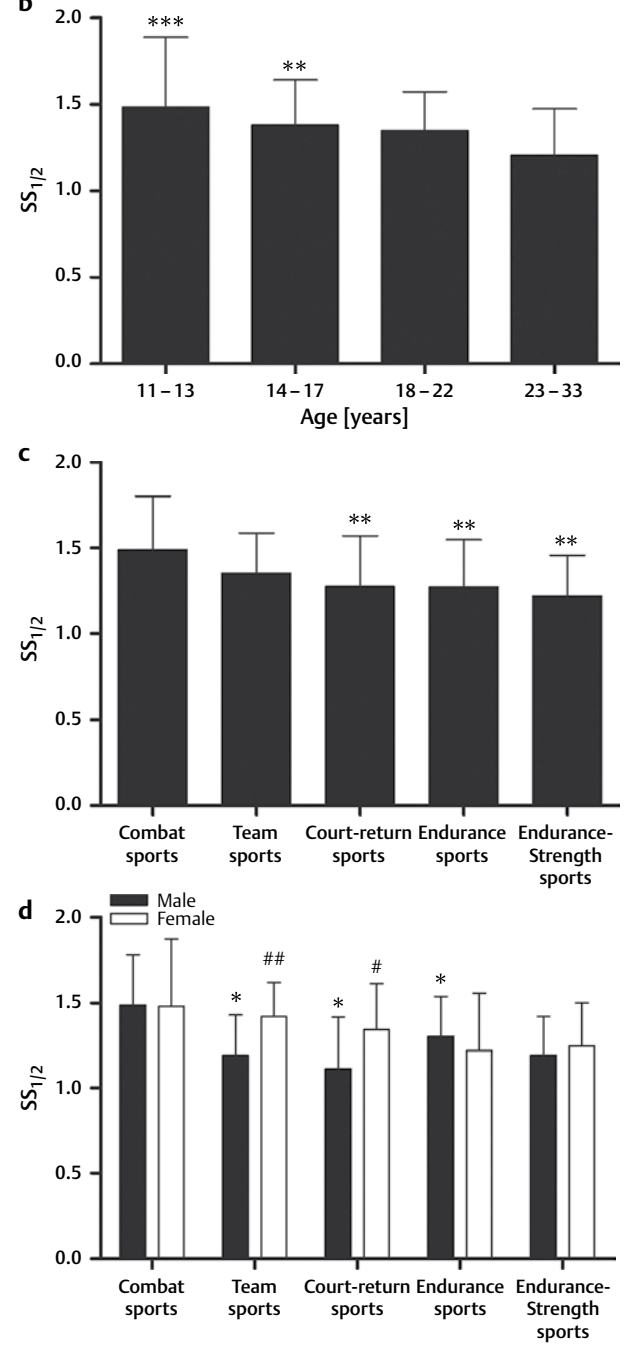

Fig. 3 a SS1/2 of athletes separated by age and gender. * Significant difference $(\mathrm{P}<0.05),{ }^{* *}(\mathrm{P}<0.01),{ }^{* * *}(\mathrm{P}<0.001)$ to male age group 11 to 13 ; \# significant difference $(P<0.05)$ to male age group 18 to $22 ; \S \S$ significant difference $(P<0.01)$ to male of same age. $\mathbf{b}$ SS1/2 of athletes separated by age groups. ${ }^{*} *$ Significant difference $(P<0.01),{ }^{* * *}(P<0.001)$ to age group 23 to 33 . c SS1/2 of athletes separated by sport type. ** Significant difference $(\mathrm{P}<0.05)$ to Combat sports. $\mathbf{d}$ SS1/2 of athletes separated by sport type and gender. * Significant difference $(P<0.05)$ to male Combat sport; \# significant difference $(P<0.05)$, \#\# $(P<0.01)$ to male of same sports. 


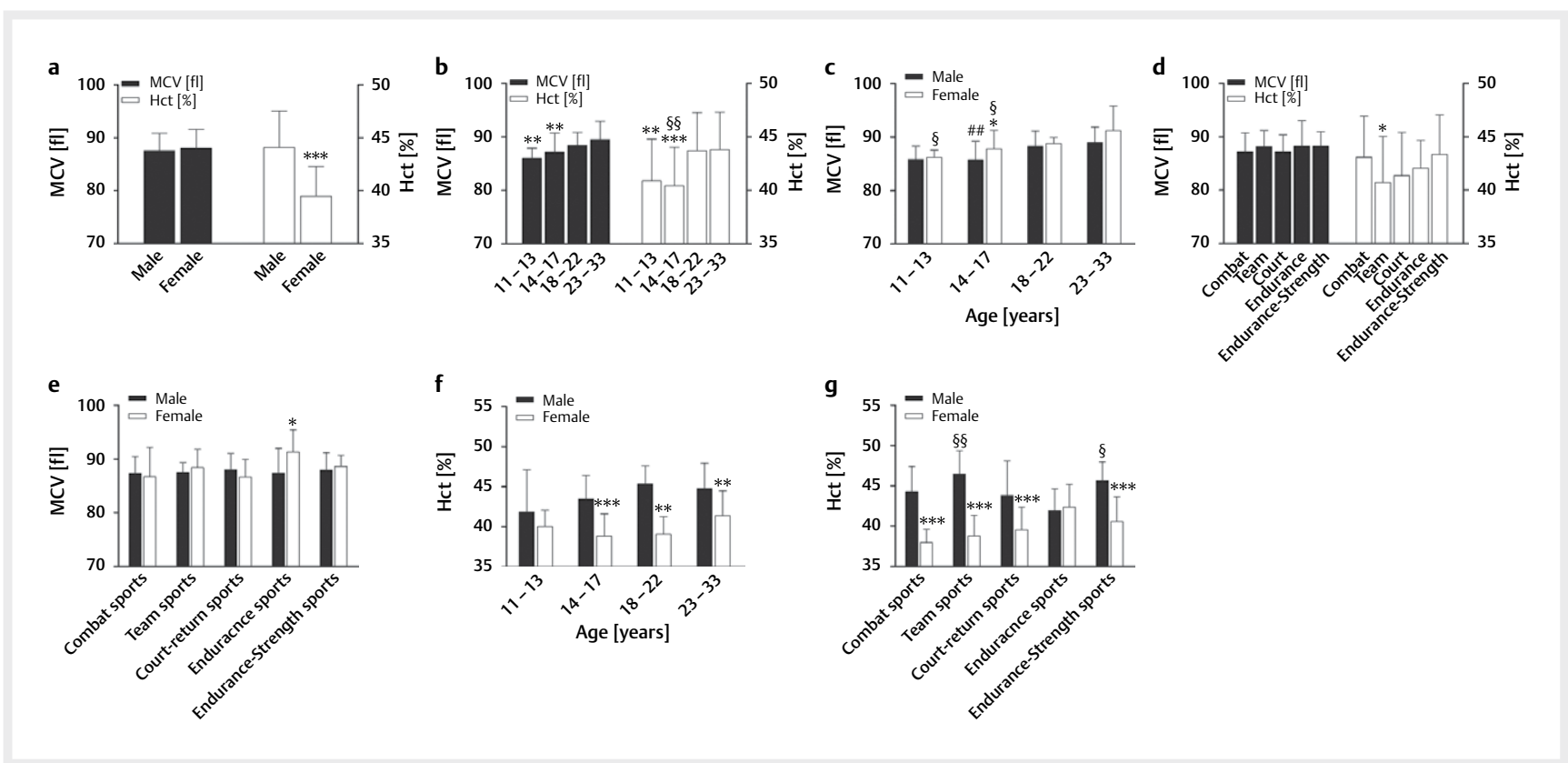

- Fig. 4 a MCV and Hct of athletes separated by gender. ${ }^{* * *}$ Significant difference $(\mathrm{P}<0.001)$ to male. $\mathbf{b} \mathrm{MCV}$ and Hct of athletes separated by age groups. ${ }^{* *}$ Significant difference $(\mathrm{P}<0.01),{ }^{* * *}(\mathrm{P}<0.001)$ to age group 23 to 33 ; $\S \S$ significant difference $(\mathrm{P}<0.01)$ to age group 18 to 22 . $\mathrm{c} \mathrm{MCV}$ of athletes separated by age and gender. ${ }^{*}$ Significant difference $(P<0.05)$ to male of same age; \#\# significant difference $(P<0.01)$ to male age group 23 to 33. § significant difference $(P<0.05)$ to female age group 23 to 33 . d MCV and Hct of athletes separated by sport type. * significant difference $(P<0.05)$ to and Endurance-Strength sports. e MCV of athletes separated by sport type and gender. ${ }^{*}$ Significant difference $(P<0.05)$ to male of same sport type. $\mathbf{f H c t}$ of athletes separated by age and gender. ${ }^{* *}$ Significant difference $(\mathrm{P}<0.01),{ }^{* * *}(\mathrm{P}<0.001)$ to male of same age group. $\mathbf{g}$ Hct of athletes separated by sport type and gender. ${ }^{* * *}$ Significant difference $(P<0.001)$ to male of same sport type; $\S(P<0.05)$, $\S \S$ $(\mathrm{P}<0.01)$ to male Endurance sports.

\section{Mean cellular volume and Hematocrit}

Analyses with gender and age group as factors revealed no effect of gender on MCV ( $>$ Fig. 4s), but a significant effect $(P<0.001)$ of the age groups on MCV ( $\triangleright$ Fig. 4b). No age group X gender interaction was observed. Post hoc analyses revealed higher MCV in age group 23 to 33 compared to age groups 11 to 13 and 14 to 17 $(\mathrm{P}<0.01$; Fig. 4b). Separated by gender, female athletes of the age group 14 to 17 showed higher $(p<0.05)$ MCV values compared to male athletes. Within male athletes, age group 18 to 22 showed higher MCV values compared to age group 14 to $17(\mathrm{P}<0.01)$. Within female athletes, age group 23 to 33 showed higher values compared to age groups 11 to 13 and 14 to 17 ( $P<0.05$; $>$ Fig. $4 \mathbf{c}$ ).

Analyses with gender and sport type as factors revealed no effect of sport type or sport type X gender on MCV ( $>$ Fig. 4d). However, separated by gender, post hoc analyses revealed higher $(\mathrm{P}<0.05)$ MCV values for female Endurance athletes ( $>$ Fig. 4e).

Analyses with gender and age group as factors revealed a significant effect of gender $(\mathrm{P}<0.001)$ on Hct ( $>$ Fig. $4 a)$ and a significant effect of age groups $(\mathrm{P}<0.05)$ on Hct ( $\triangleright$ Fig. $\mathbf{4 b}$ ). Post hoc analyses revealed higher $\mathrm{Hct}$ in age group 23 to 33 compared to age groups 11 to $13(P<0.01)$ and 14 to $17(P<0.001)$. Lower Hct was detected in age group 14 to 17 compared to age group 18 to 22 ( $\mathrm{P}<0.01$; $>$ Fig. 4b). Separated by gender, female athletes showed lower Hct in age groups 13 to $17(\mathrm{P}<0.001), 18$ to 22 and 23 to $33(\mathrm{P}<0.01)$. Within male or female athletes, no difference was observed ( $\vee$ Fig. $\mathbf{4 f}$ ).
Analyses with gender and sport type as factors revealed no effect of sport type on $\mathrm{Hct}$, but an effect of the sport type $X$ gender interaction on $\mathrm{Hct}(\mathrm{P}<0.01$, $>$ Fig. $\mathbf{4 g})$. Post hoc analyses revealed lower Hct values in Team sports compared to Combat and Endurance-Strength sports ( $\mathrm{P}<0.05$; $>$ Fig. $4 d$ ). Separated by gender, female athletes of all sport types except for Endurance sports showed lower $(P<0.001)$ Hct values compared to male athletes of the same sport type. Within male athletes, Endurance sports showed lower Hct values compared to Team sports $(P<0.01)$ and EnduranceStrength sports ( $\mathrm{P}<0.05$; $>$ Fig. $\mathbf{4 g})$.

Regression analyses revealed negative correlation between ElRatio and $\mathrm{MCV}\left(\mathrm{R}=-0.37 ; \mathrm{R}^{2}=0.13 ; \mathrm{P}<0.001\right)$ and $\mathrm{El}_{\text {Ratio }}$ and $\mathrm{Hct}$ $\left(R=-0.41 ; R^{2}=0.18 ; P<0.001\right)(\vee$ Fig. $5 \mathbf{a}+\mathbf{b}) . \mathrm{EI}_{\max }$ and MCV were positively correlated, but $\mathrm{EI}_{\max }$ and Hct showed no correlation $(\triangleright$ Fig. $\mathbf{5 c}+\mathbf{d}) . \mathrm{SS}_{1 / 2}$ and MCV and Hct, respectively, were negatively correlated ( $\vee$ Fig. $\mathbf{5 e}+\mathbf{f})$.

\section{Discussion}

This study investigated baseline RBC deformability values in athletes of different sport types, age and gender because only little data are available in the literature so far. Increased RBC deformability is a major determinant of oxygen supply of the working muscle and thus of athletic performance, since only highly deformable RBC can provide optimal oxygen perfusion [21]. 


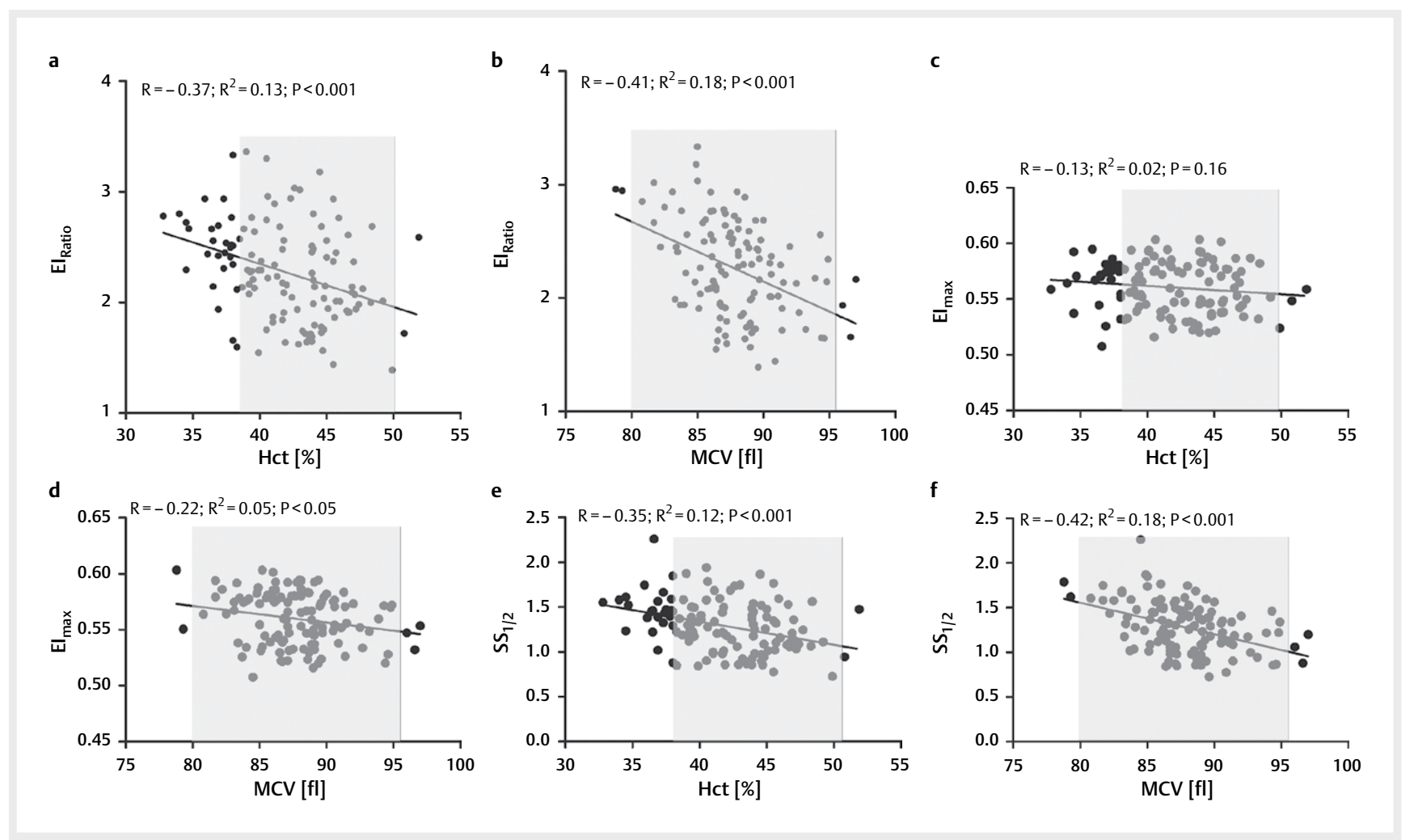

- Fig. 5 a Correlation analyses of EIRatio and Hct [Grey background indicates normal range (Hct: 38-50\%)]. b Correlation analyses of EIRatio and MCV [Grey background indicates normal range (MCV: 80-96 fl)]. c Correlation analyses of Elmax and Hct [Grey background indicates normal range (Hct: 38-50\%)] d Correlation analyses of Elmax and MCV [Grey background indicates normal range (MCV: 80-96 fl)]. e Correlation analyses of SS1/2 and Hct [Grey background indicates normal range (Hct: 38-50\%)]. f Correlation analyses of SS1/2 and MCV [Grey background indicates normal range (MCV: 80-96 fl)].

The present data indicate no difference in RBC deformability $\left(\mathrm{El}_{\text {Ratio }}, \mathrm{EI}_{\max }, \mathrm{SS}_{1 / 2}\right)$ between overall populations of male and female athletes. Previous findings with adult, but non-athlete participants show that premenopausal women show higher RBC deformability compared to adult men. This was explained by the regular physiologic menstruation. During menstruation, old and rigid RBC are removed from the body which leads to a rejuvenation of the entire RBC population of pre-menopausal women [19]. The lack of significant differences between male and female athletes might be explained by the fact that neither the time of menstrual circle was registered nor was it registered if female athletes used contraceptives. Both were shown to influence RBC deformability [15]. But, the main difference to the present literature is that only athletes are recruited in the present study. The hemorheologic and hematological profile of athletes differs from the profile of non-athletes. Chronic and regular training results in a hemorhologic fitness, which is characterized by a lower Hct, a lower blood and plasma viscosity and a higher RBC deformability in athletes compared to non-athletes [7]. Besides, extensive training volumes have been associated to intravascular hemolysis of primarily old and rigid RBC in both, male and female athletes. This increases RBC turnover and leads to rejuvenation of the $R B C$ population $[21,30]$. It is known that the mean RBC age is reduced from $113.1 \pm 31.0$ days in male and $114.1 \pm 29.0$ days in female sedentary controls to $67.2 \pm 22.2$ days in male and to $72.4 \pm 26.0$ days in female en- durance distance runners [37]. This might indicate that RBC deformability in general might not differ between adult male and female endurance athletes.

Young RBC are more flexible compared to older RBC and a lower average age of the entire RBC population might result in higher deformability. Further, endurance athletes are shown to possess a higher level of membrane fluidity of RBC which can be described by modifications in the lipid profile that lead to an improvement of the RBC membrane fluidity that might also positively affect RBC deformability and ease the passage of RBC through capillaries $[18,25]$.

RBC deformability, separately analyzed by age of the athletes, gradually increased from pre-puberty to adulthood, when interpreting values of $\mathrm{El}_{\text {Ratio }}$ and $\mathrm{SS}_{1 / 2}$. However, $\mathrm{EI}_{\max }$ values are lower in the age group 23 to 33 . Both parameters $\left(\mathrm{EI}_{\max }\right.$ and $\left.\mathrm{SS}_{1 / 2}\right)$ represent RBC deformability. $\mathrm{EI}_{\max }$ is a theoretical value of maximum deformability and it is possible that a further increase is not possible because maximum is reached in age group 18 to $22 . \mathrm{SS}_{1 / 2}$ is defined as shear stress needed to achieve one half Elmax. If $\mathrm{SS}_{1 / 2}$ decreases less pressure is needed to deform the RBC and this might be related to improved membrane-cytoskeleton interaction. RBC deformability is further determined by cytoplasmic viscosity (i. e. intracellular hemoglobin solution) and the resting cell shape (i. e. biconcave disc or altered morphology), which determine the membrane surface area to cell volume ratio and the viscoelastic properties of 
the cell membrane [26]. The human RBC is deformable due to its low cytoplasmic viscosity and the ability of the membrane to freely rotate around the cytoplasm. Alterations of these physical properties can reduce deformability. $\mathrm{EI}_{\max }$ is mainly affected by cell shape and geometry as well as membrane properties and can be reduced by changes of these parameters. $\mathrm{EI}_{\max }$ is measured at infinite shear stress and thus, cytoplasmic viscosity is not relevant [1].

Moreover, it is possible that lower $\mathrm{SS}_{1 / 2}$ and $\mathrm{El}_{\text {Ratio }}$ values in older athletes might result from improved nitric oxide availability because of a longer training history. It was previously shown that nitric oxide binds to the cytoskeletal proteins a- and ß-spectrin which was associated with increased RBC deformability [14]. Further, it was shown that deformability at rest increases with increasing training volume $[11,20]$. Therefore, it might be concluded that RBC deformability improves until adulthood is reached. When further divided by gender, $\mathrm{El}_{\text {Ratio }}$ and $\mathrm{SS}_{1 / 2}$ showed no difference between the different female groups from pre-puberty, puberty to adults, which might be in part be explained by the use of contraceptives [15], but this was not evaluated in the present study. However, $\mathrm{EI}_{\max }$ of female athletes increases up to age group 18 to 22, which might be explained by maturanional processes. In contrast, male athletes older than 13 years showed higher RBC deformability, with respect to ElRatio and $\mathrm{SS}_{1 / 2}$, compared to male athletes younger 13 years. It is suggested that the onset of the sex hormone testosterone might affect the RBC system and thus RBC deformability. It was shown that androgens, respectively testosterones, stimulate erythropoiesis which increases bone marrow activity and possibly affects the amount of young RBC that show better deformability $[3,28]$. The data of the present study indicate that Hct increases after the age of 13 in the male study population and reach highest values in adult age which might result from the higher stimulation of erythropoiesis.

$M C V$ is also known to affect RBC deformability and the present data showed an increase in MCV from young to mature athletes and are thus in line with the RBC deformability data. Further, the data revealed a negative correlation between $\mathrm{MCV}$ and $\mathrm{El}_{\text {Ratio }}$ and $S_{1 / 2}$, respectively and a positive correlation between MCV and $\mathrm{EI}_{\max }$. These findings suggest that the low deformability values found in young athletes were associated to lower MCV while higher MCV of adult athletes might cause the increase in RBC deformability. These results are line with the similar findings in RBC deformability as RBC deformability and MCV correlate [34].

When MCV values were further separated by gender, no difference between male and female athletes of any age is detected. Also, no gender related differences where found between sport groups, with the only exeption in Endurance sports where female athletes show higher MCV values compared to male counterparts.

Hct was previously described to affect RBC deformability, since a low Hct goes along with a higher RBC deformability in athletes as part of the hemorheologic fitness [7]. It was observed that Hct negatively correlates with maximal aerobic capacity and was the best determinant of $\mathrm{VO}_{2}$ max in athletes [13]. However, an increase of Hct to supra-normal levels might increase exercise capacity of well trained athletes which is, among others, achieved by high altitude taining regimens and a thus achieved increased level of erythropoietin [27]. Brun et al. observed no correlation between aerobic fitness and Hct in professional soccer players [8]. In the present study, athletes of Team sports show lower Hct compared to Endurance-Strengt sport athletes. This might be explained by the lower age of the Team sports group.

In the present study, Hct levels were mainly within normal range but lowest in youngest athletes and highest in oldest athletes. Female athletes show lower Hct than men which is in line with previous data. Gender related differences are observed in age groups older than 13 years. After this age hormonal changes might have an influence on hemorheologic and hematoloc parameters [19]. A positive correlation between $\mathrm{Hct}$ and $\mathrm{El}_{\text {Ratio }}$ and $\mathrm{SS}_{1 / 2}$, respectively was calculated and considering the MCV values it is suggested that modification of the RBC system occurs during adulthood. This might include increases in hemoglobin content and RBC mass [35]. Significant differences were found for $\mathrm{El}_{\text {Ratio }}$ with higher values observed in the Combat sports compared to all other sport groups. Also $\mathrm{SS}_{1 / 2}$ is higher in the Combat sports group compared to the other sport groups. However, when interpreten $\mathrm{EI}_{\max }$ Combat sports show higher values compared to Court-return and Endurance-Strength sports. When interpreting $\mathrm{El}_{\text {Ratio }}$ and $\mathrm{SS}_{1 / 2}$, we might conclude that Combat sports are rather strength dominated compared to the four other sport groups [23]. Data reveal that RBC deformability is higher in endurance dominated sports, which showed highest RBC deformability in the values $\mathrm{SS}_{1 / 2}$ and $\mathrm{El}_{\text {Ratio }}$. This might be explained by a general high chronic training load with high endurance rate of every athlete resulting in a high RBC turnover [9, 30]. High RBC turnover is also the result of intravascular hemolysis, due to compression of the capillaries by large muscle groups, and footstrike hemolysis [33] which is not only described for endurance athletes but also for other sports such as karate, weight-lifting and rowing [32]. Further, it was shown that an acute bout of intensive cycling exercise leads to intra-vascular hemolytic processes which include alternations in $\alpha$ - and $\beta$ - spectrin [4]. An explanation for the lack of significant differences in RBC deformability between Endurance, Endurance-Strength, Court-return and Team sports might be that all athletes who perform on a top level show a well established aerobic capacity which is due to a high endurance training load in training. Significant difference in RBC deformability between these different sport groups thus seem to be unlikely. Further, a crosssectional study by Zinner and colleagues [40] showed that the $\mathrm{VO}_{2}$ peak values of nearly 500 athletes of different sport types did not significantly differ. In line with the similar deformability values are similar MCV and Hct values in all sport type groups indicating a similar average age of the entire RBC population. Besides, all Hct values are in normal range ranging from $40.72 \pm 4.32$ in Team sports to $43.36 \pm 3.70$ in Endurance-Strength sports. Weight and colleagues showed that no difference in Hct was found between endurance athletes and controls in adult male and female participants [36]. The finding in the present study that female athletes of Team sports show lower RBC deformability $\left(\mathrm{EI}_{\text {Ratio }}\right.$ and $\left.\mathrm{SS}_{1 / 2}\right)$ than the male counterparts can be explained by the younger age of the female athletes of this group, however $\mathrm{El}_{\max }$ values are higher in female Team sport athletes. But, the lower RBC deformability (El Ratio $_{\text {R }}$ and $\mathrm{SS}_{1 / 2}$ ) in female Court-return athletes cannot be explained by different age but may be related to the ingestion of hormonal contraceptives. Thus, further investigations are needed to detect a possible impact of hormonal contraceptives on RBC deformability. 


\section{Conclusion}

This study first time describes the effects of sport, gender and age of the elite athlete on RBC deformability. RBC deformability mainly seems to be influenced by the age of the athlete because of changes in MCV and Hct. But also endurance load of the training might positively affect RBC deformability.

\section{Acknowledgments}

The authors would like to thank Anke Schmitz for their excellent technical assistance.

\section{Funding}

This research did not receive any specific grant from funding agencies in the public, commercial, or not-for-profit sectors.

\section{References}

[1] Baskurt OK, Hardeman MR, Uyuklu M, Ulker P, Cengiz M, Nemeth N, Meiselman HJ. Parameterization of red blood cell elongation index shear stress curves obtained by ektacytometry. Scand J Clin Lab Invest Suppl 2009; 69: 777-788

[2] Baskurt OK, Meiselman HJ. Data reduction methods for ektacytometry in clinical hemorheology. Clin Hemorheol Microcirc 2013; 54: 99-107

[3] Beggs LA, Yarrow JF, Conover CF, Meuleman JR, Beck DT, Morrow M, Borst SE. Testosterone alters iron metabolism and stimulates red blood cell production independently of dihydrotestosterone. Am J Physiol 2014; 307: E456-E461

[4] Beneke R, Bihn D, Hütler M, Leithäuser RM. Haemolysis caused by alterations of alpha- and beta-spectrin after 10 to $35 \mathrm{~min}$ of severe exercise. Eur J Appl Physiol 2005; 95: 307-312

[5] Bizjak DA, Brinkmann C, Bloch W, Grau M. Increase in red blood cell-nitric oxide synthase dependent nitric oxide production during red blood cell aging in health and disease: A study on age dependent changes of rheologic and enzymatic properties in red blood cells. PLoS One 2015; 10: e0125206

[6] Bosman G]CGM, Lasonder E, Groenen-Döpp YAM, Willekens FLA, Werre JM, Novotný VMJ. Comparative proteomics of erythrocyte aging in vivo and in vitro. J Proteomics 2010; 73: 396-402

[7] Brun JF, Varlet-Marie E, Connes P, Aloulou I. Hemorheological alterations related to training and overtraining. Biorheology 2010; 47: 95-115

[8] Brun JF, Varlet-Marie E, Fédou C, Raynaud de Mauverger E. One-year follow-up of blood viscosity factors and hematocrit/viscosity ratio in elite soccer players. Clin Hemorheol Microcirc 2016; 64: 799-808

[9] Caimi G, Canino B, Amodeo G, Ingargiola P, Lucido D, Calandrino V, Lo Presti R. Erythrocyte deformability and nitric oxide Metabolites in athletes before and after a cardiopulmonary test. Clin J Sport Med 2009; 19: 306-310

[10] Connes P, Bouix D, Py G, Prefaut C, Mercier ], Brun JF, Caillaud C. Opposite effects of in vitro lactate on erythrocyte deformability in athletes and untrained subjects. Clin Hemorheol Microcirc 2004; 31: 311-318

[11] Filipovic A, Kleinöder H, Plück D, Hollmann W, Bloch W, Grau M. Influence of whole-body electrostimulation on human red blood cell deformability. J Strength Cond Res 2015; 29: 2570-2578

[12] Franco RS. The measurement and importance of red cell survival. Am J Hematol 2009; 84: 109-114
[13] Gaudard A, Varlet-Marie E, Bressolle F, Mercier ], Brun JF. Hemorheological correlates of fitness and unfitness in athletes: Moving beyond the apparent "paradox of hematocrit"? Clin Hemorheol Microcirc 2003; 28: 161-173

[14] Grau M, Pauly S, Ali J, Walpurgis K, Thevis M, Bloch W, Suhr F. RBC-NOS-dependent s-nitrosylation of cytoskeletal proteins improves RBC deformability. PLoS One 2013; 8: e56759

[15] Guillet R, Driss F, Perrotin P, Pautou C, Nalpas B, Boynard M. Gender, menstrual cycle, oral contraceptives and red blood cell deformability in healthy adult subjects. Clin Hemorheol Microcirc 1998; 19: 83-88

[16] Hardeman MR, Dobbe JG, Ince C. The laser-assisted optical rotational cell analyzer (LORCA) as red blood cell aggregometer. Clin Hemorheol Microcirc 2001; 25: 1-11

[17] Harriss DJ, Atkinson G. Ethical standards in sport and exercise science research: 2016 update. Int J Sports Med 2015; 36: 1121-1124

[18] Kamada T, Tokuda S, Aozaki S, Otsuji S. Higher levels of erythrocyte membrane fluidity in sprinters and long-distance runners. J Appl Physiol 1993; 74: 354-358

[19] Kameneva MV, Watach MJ, Borovetz HS. Gender difference in rheologic properties of blood and risk of cardiovascular diseases. Clin Hemorheol Microcirc 1999; 21: 357-363

[20] Koliamitra C, Holtkamp B, Zimmer P, Bloch W, Grau M. Impact of training volume and intensity on RBC-NOS/NO pathway and endurance capacity. Biorheology 2017 Advance online publication

[21] Mairbäurl H. Red blood cells in sports: Effects of exercise and training on oxygen supply by red blood cells. Front Physiol 2013; 4: 1-13

[22] Mchedlishvili G, Maeda N. Blood flow structure related to red cell flow: Determinant of blood flow in narrow microvessels. Jpn J Physiol 2001; 51: $19-30$

[23] Nader GA. Concurrent strength and endurance training: From molecules to man. Med Sci Sports Exerc 2006; 38: 1965-1970

[24] Nageswari K, Banerjee R, Gupte RV, Puniyani RR. Effects of exercise on rheological and microcirculatory parameters. Clin Hemorheol Microcirc 2000; 23: 243-247

[25] Nakano T, Wada Y, Matsumura S. Membrane lipid components associated with increased filterability of erythrocytes from long-distance runners. Clin Hemorheol Microcirc 2001; 24: 85-92

[26] Rabai M, Detterich JA, Wenby RB, Toth K, Meiselman H]. Effects of ethanol on red blood cell rheological behavior. Clin Hemorheol Microcirc 2014; 56: 87-99

[27] Reinhart WH. The optimum hematocrit. Clin Hemorheol Microcirc 2016; 64: 575-585

[28] Shahani S, Braga-Basaria M, Maggio M, Basaria S. Androgens and erythropoiesis: Past and present. J Endocrinol Invest 2009; 32: 704-716

[29] Shaskey D], Green GA. Sports Haematology. Sports Med 2000; 29 : 27-38

[30] Smith JA, Martin DT, Telford RD, Ballas SK. Greater erythrocyte deformability in world-class endurance athletes. Am J Physiol 1999; 276: 2188-2193

[31] Suhr F, Brenig J, Muller R, Behrens H, Bloch W, Grau M. Moderate exercise promotes human RBC-NOS activity, NO production and deformability through Akt kinase pathway. PLoS One 2012; 7 (9): e45982

[32] Szygula Z. Erythrocytic system under the influence of physical exercise and training. Sports Med 1990; 10: 181-197

[33] Telford RD, Sly G], Hahn AG, Cunningham RB, Bryant C, Smith JA. Footstrike is the major cause of hemolysis during running. J Appl Physiol 2003; 94: 38-42 
[34] Tempelhoff GFV, Schelkunov O, Demirhan A, Tsikouras P, Rath W, Velten E, Csorba R. Correlation between blood rheological properties and red blood cell indices (MCH, MCV, MCHC) in healthy women. Clin Hemorheol Microcirc 2016; 62: 45-54

[35] Ulrich G, Bartsch P, Friedmann-Bette B. Total haemoglobin mass and red blood cell profile in endurance-trained and non-endurance-trained adolescent athletes. Eur J Appl Physiol 2011; 111: 2855-2864

[36] Weight LM, Klein M, Noakes TD, Jacobs P. 'Sports anemia' -a real or apparent phenomenon in endurance-trained athletes? Int J Sports Med 1992; 13: 344-347

[37] Weight LM, Byrne M], Jacobs P. Haemolytic effects of exercise. Clin Sci 1991; 81: 147-152
[38] Weineck ].(ed) Optimales training: Leistungsphysiologische trainingslehre unter besonderer berücksichtigung des kinder- und jugendtrainings. Balingen: Spitta; 2010

[39] Yalcin O, Erman A, Muratli S, Bor-Kucukatay M, Baskurt OK. Time course of hemorheological alterations after heavy anaerobic exercise in untrained human subjects. J Appl Physiol 2003; 94: 997-1002

[40] Zinner C, Sperlich B, Wahl P, Mester J. Classification of selected cardiopulmonary variables of elite athletes of different age, gender, and disciplines during incremental exercise testing. Springerplus 2015; 4: 544 